\title{
Scanning nanoscale multiprobes for conductivity measurements
}

\author{
Bøggild, Peter; Hansen, Torben Mikael; Kuhn, Oliver; Grey, Francois; Junno, T.; Montelius, L.
}

Published in:

Review of Scientific Instruments

Link to article, DOI:

$10.1063 / 1.1150692$

Publication date:

2000

Document Version

Publisher's PDF, also known as Version of record

Link back to DTU Orbit

Citation (APA):

Bøggild, P., Hansen, T. M., Kuhn, O., Grey, F., Junno, T., \& Montelius, L. (2000). Scanning nanoscale multiprobes for conductivity measurements. Review of Scientific Instruments, 71(7), 2781-2783. https://doi.org/10.1063/1.1150692

\section{General rights}

Copyright and moral rights for the publications made accessible in the public portal are retained by the authors and/or other copyright owners and it is a condition of accessing publications that users recognise and abide by the legal requirements associated with these rights.

- Users may download and print one copy of any publication from the public portal for the purpose of private study or research.

- You may not further distribute the material or use it for any profit-making activity or commercial gain

- You may freely distribute the URL identifying the publication in the public portal 


\title{
Scanning nanoscale multiprobes for conductivity measurements
}

\author{
P. Bøggild, ${ }^{\text {a) }}$ T. M. Hansen, O. Kuhn, and F. Grey \\ Mikroelektronik Centret, Technical University of Denmark, DK-2800 Lyngby, Denmark \\ T. Junno and L. Montelius \\ Department of Solid State Physics, Lund University, Box 118, S221 00 Lund, Sweden
}

(Received 10 February 2000; accepted for publication 27 March 2000)

\begin{abstract}
We report fabrication and measurements with two- and four-point probes with nanoscale dimensions, for high spatial resolution conductivity measurements on surfaces and thin films. By combination of conventional microfabrication and additive three-dimensional nanolithography, we have obtained electrode spacings down to $200 \mathrm{~nm}$. At the tips of four silicon oxide microcantilevers, narrow carbon tips are grown in converging directions and subsequently coated with a conducting layer. The probe is placed in contact with a conducting surface, whereby the electrode resistance can be determined. The nanoelectrodes withstand considerable contact force before breaking. The probe offers a unique possibility to position the voltage sensors, as well as the source and drain electrodes in areas of nanoscale dimensions. (C) 2000 American Institute of Physics.
\end{abstract}

[S0034-6748(00)02607-1]

\section{INTRODUCTION}

Four-point measurements have played an important role in understanding the electrical properties of solid state bulk materials and films for many decades. ${ }^{1}$ A typical four-point configuration is a linear array of four equidistant electrodes, with two outer electrodes performing as source and drain, while the voltage difference is measured across the inner electrodes. The conductivity can be derived from the voltage-to-current ratio, while compensating for geometrical effects related to the thickness, size, and shape of the sample. Due to the electrical separation of the source-drain electrodes and the voltage electrodes, the conductivity is measured essentially without contact resistance. Common types of fourpoint probes are macroscopic spring-loaded electrodes, that can be positioned freely on a surface, ${ }^{2}$ and smaller, lithographically fabricated in-plane electrodes fixed on the surface. ${ }^{3}$ The macroprobes are in many cases inconvenient because of their size and the large contact forces exerted on the samples, while the in-plane electrodes cannot be repositioned. The four-point technique is suited where the conductivity varies slowly on the scale of the electrode spacing. ${ }^{4}$ In order to measure systems that exhibit conductivity variations on a small scale, it is preferable to reduce the electrode spacing below the relevant scale, yet maintaining the ability to reposition them. Later we describe a solution to this challenge.

\section{PROBE FABRICATION}

Using conventional photolithographic microprocessing techniques, we have fabricated four-point probes consisting of four soft and flexible metallized $\mathrm{SiO}_{2}$ microcantilevers, ${ }^{4}$ with electrode spacings down to $1.5 \mu \mathrm{m}$, as shown in Fig. 1(b). To reduce the gap even further, we take advantage of

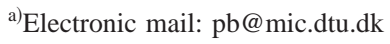

electron-beam induced deposition, which is a constructive three-dimensional nanolithography technique. ${ }^{5-10}$ By focusing the electron beam of a scanning electron microscope on the ends of the microcantilevers, hydrocarbon molecules present in small concentrations near the beam spot are cracked. This leads to the formation of a narrow rod of carbon residues, growing in the direction of the beam. Lengths of several microns are easily obtained by continuation of the process, and such tips have successfully been used for high aspect ratio atomic force microscopy tips, ${ }^{5}$ nanoparticle manipulation, ${ }^{6}$ and nanolithography. ${ }^{7,8}$

To avoid charging of the oxide cantilevers by the electron beam, and thus a poor growth rate and tip quality, ${ }^{7}$ the microcantilevers are coated with a thin metallic layer $(100 \AA$ $\mathrm{Ti} / 800 \AA \mathrm{Au}$ ) prior to tip deposition. By keeping the electrodes at the ground potential of the scanning electron microscope (SEM), a drain for the electron beam is provided. In order to make the nanotips conducting the nanotips are metallized a second time (100 $\AA \mathrm{Ti} / 600 \AA \mathrm{Au})$. An alternative approach could be to grow the tips in the presence of controlled amounts of metallo-organic compounds inside the vacuum chamber. ${ }^{9,10}$

We used a JEOL 6340F field emission microscope operating at a base pressure of $10^{-8}$ Torr. With an acceleration voltage of $10 \mathrm{kV}$ and beam currents in the range 3-6 pA we obtained a growth rate of $250 \mathrm{~nm} / \mathrm{min}$. The beam current is comparable to the $1.9 \mathrm{pA}$ found to be optimal by Wendel et al. ${ }^{7}$ in terms of growth rate and resulting sharpness of the tips. Similarly to these findings, ${ }^{7}$ we observe a decay of the growth rate as the tip grows longer.

The carbon tips turn out to be mechanically strong and durable, as demonstrated in earlier works. ${ }^{6,7}$ It has been suggested that the tip material is diamond-like, without being brittle, which would explain the exceptional durability. ${ }^{7}$

By tilting the microprobe with respect to the beam, we grow nanotips in converging directions, eventually forming 

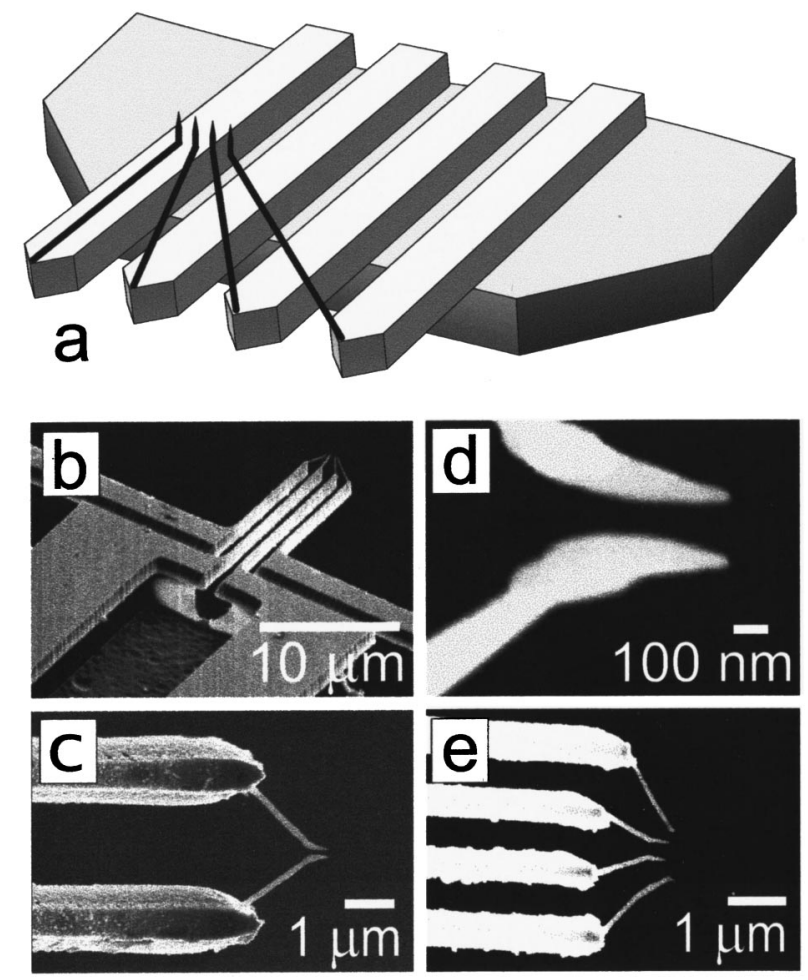

FIG. 1. (a) Schematic of the nanotips deposited in a plane perpendicular to the plane of the microcantilevers. (b) SEM image of microfour-point probe with $4 \mu \mathrm{m}$ spacing. (c) SEM image of nanotwo probe with $200 \mathrm{~nm}$ spacing, imaged at an angle of $45^{\circ}$. (d) Close up of $200 \mathrm{~nm}$ gap two-probe. (e) SEM image of nanofour-point probe with an average spacing of $350 \mathrm{~nm}$.

multipoint probes with nanoscale electrode gaps, in a plane perpendicular to the plane of the microcantilevers [see Fig. 1(a)]. In Fig. 1(c) a SEM image of a two-probe with a 200 $\mathrm{nm}$ gap is shown. To fine tune the gap and lengths of the tips, parallel secondary tips are added to the converging primary tips. The tips are grown in an alternating, iterative fashion, using successively shorter deposition times. The final adjustments are done with deposition times of about $5 \mathrm{~s}$, allowing the gap and tip lengths to be tuned to within $10 \mathrm{~nm}$ [see Fig. 1(d)]. In Fig. 1(e) an example of a four-point probe with an average spacing of $330 \mathrm{~nm}$ is shown. Larger four-point probes have been fabricated with tip lengths of up to $3.5 \mu \mathrm{m}$ and gaps of $500 \mathrm{~nm}$.

\section{EXPERIMENTAL TESTS}

For testing the nano four-point probes we used a silicon substrate covered with a $1000 \AA$ thin gold film, located on an $x y z$ stage for positioning with $100 \mathrm{~nm}$ accuracy. The probe is mounted at an angle of $30^{\circ}$ with respect to the sample, in the focal point of a high-resolution video microscope. A laser beam is directed towards the microcantilever, so that four spots of reflected light are visible in the video microscope. ${ }^{4}$ When the cantilevers touch down onto the sample, a slight deflection leads to a measurable change in reflection intensity, allowing accurate control of the contact pressure. Due to their small diameter, the tips cannot themselves be resolved optically.

Figure 2 illustrated the measurement setup. An electronic switch in turn connects each electrode to an alternating

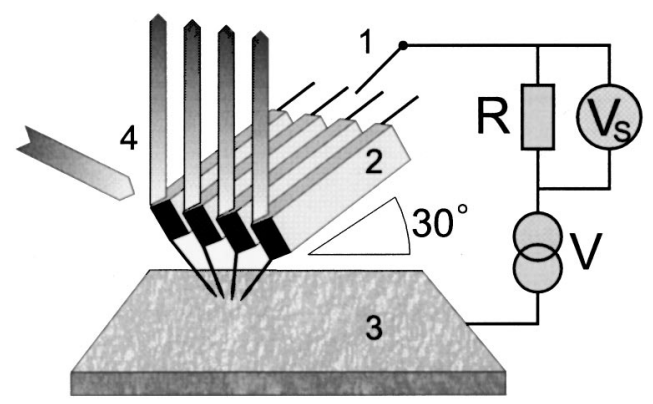

FIG. 2. Illustration of test setup. An electronic switch (1) in turn connects the electrodes to a two-point measurement circuit. The probe (2) is tilted $30^{\circ}$ with respect to the sample (3). An $x y z$ stage positions the sample with respect to the probe. A laser beam (4) reflected on the four microcantilevers allows monitoring of the deflection. The resistance is extracted from the voltage drop $V_{s}$ over the known resistor $R$.

current voltage source $V$, which is connected to the sample through a series resistor $R$. When electrical contact is established to the sample, the voltage drop $V_{s}$ across the series resistor can be used to determine the combined resistance, $R_{s}=\left(V / V_{s}-1\right) R$, of the contact area, the electrode, the sample, and the electronic switch.

With this setup an upper limit for the individual resistance of the electrodes can be determined as a function of the vertical sample position (see Fig. 3). Upon contact [down arrow, Fig. 3(a)] the resistance drops from about $30 \mathrm{M} \Omega$ to 1 $\mathrm{k} \Omega$ for electrodes 1,2 , and 3 , which electrode 4 does not conduct. Upon retraction [up arrow, Figs. 3(a) and 3(b)] the release point is $100-300 \mathrm{~nm}$ higher than the engage point. This hysteresis is due to sticking of the gold electrodes to the gold surface.

We test the mechanical strength of all nanoelectrodes by continually moving the sample towards the probe, until we provoke mechanical breaking of the tips, which is observed

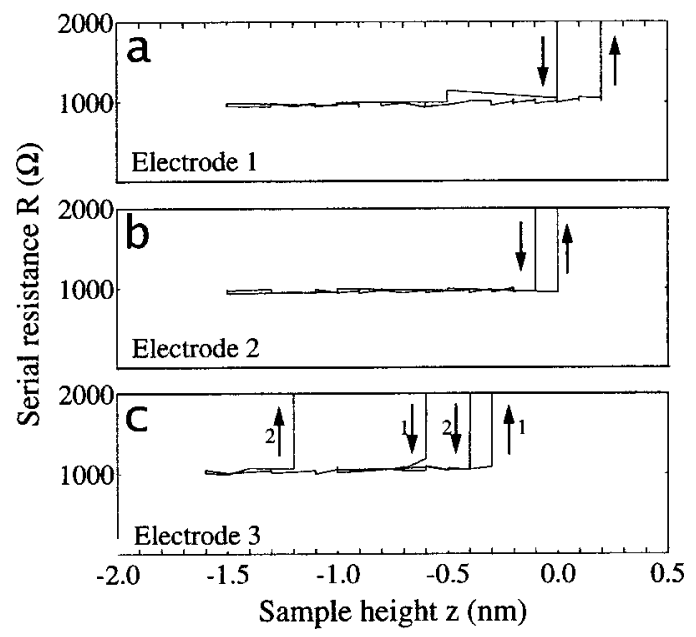

FIG. 3. Serial resistance as a function of sample height (arbitrary zero) for the three working electrodes. (a) The nanotip engages at $0.0 \mu \mathrm{m}$ but releases at $+0.2 \mu \mathrm{m}$, due to sticking. (b) Similar graph for electrode 2. (c) For electrode 3, two curves are shown. The first approach marked with 1 shows contact (down arrow) at $-0.6 \mu \mathrm{m}$ and release (up arrow) at $-0.3 \mu \mathrm{m}$. The second approach marked with 2 shows the contact occurring at $-0.4 \mu \mathrm{m}$ (down arrow), but here the probe clearly breaks at $-1.2 \mu \mathrm{m}$ (up arrow). For subsequent contacting approaches of electrode 3 , an instable contact is obtained at $-1.2 \mu \mathrm{m}$ rather than $-0.4 \mu \mathrm{m}$. 
as a sudden increase of the resistance. As seen in Fig. 3(c), electrode 3 is engaged a second time (down arrow 2), and suddenly breaks during retraction (up arrow 2). In the subsequent measurements, the contact height for electrode 3 is displaced $0.8 \mu \mathrm{m}$ further down than before the nanoprobe break. This critical deflection corresponds to a contact force of roughly $10^{-5} \mathrm{~N}$. SEM images acquired afterwards confirm that the nanoelectrodes are broken off, while the supporting microelectrodes are still intact. This behavior is also observed for electrodes 1 and 2. Despite their small dimensions, the nanoprobes are thus sufficiently robust to sustain a contact force strong enough to deflect the cantilevers by more than $1 \mu \mathrm{m}$. The $700 \mathrm{~nm}$ wide, $1500 \mathrm{~nm}$ tall microelectrodes typically break at a deflection of 3-4 $\mu \mathrm{m}$, which implies that the material composing the nanotips is substantially stronger than $\mathrm{SiO}_{2}$.

\section{SUMMARY}

In summary, we show that it is possible to make multipoint probes with electrode spacings down $200 \mathrm{~nm}$, using a combination of conventional microlithography and electron beam deposition. The new probe enables positioning of the source, drain, and voltage electrodes on the same microsized object, and thereby extends the four-point measuring technique to high spatial resolution scanning measurements. The use of flexible microcantilevers as base for the nanotips ensures that the electrodes can adapt individually to height differences on the surface. We have tested one such prototype and succeeded in establishing reliable, reproducible contact to a conducting surface.

Applications for such nanoscale multiprobe array include conductivity measurements on single atomic terraces and conducting polymer films, ${ }^{4}$ as well as magnetic and su- perconducting grains, domains and thin films. Such a probe can be used to create high resolution conductivity maps of thin films, due to reduction of the spatial range of geometric effects compared to previous experiments. ${ }^{4}$ Several fascinating prospects of a nanoscale two probe for studying mesoscopic transport on surfaces and wires have been reported in literature. $^{11,12}$ The small scale of the probe, however, requires high-resolution microscopy for accurate positioning on small objects, which can be accomplished using an in situ SEM.

\section{ACKNOWLEDGMENTS}

The authors acknowledge the technical assistance of I. Maximov and C. Thelander.

${ }^{1}$ F. M. Smits, Bell Sys. Tech. J. May (1958).

${ }^{2}$ C. L. Petersen, F. Grey, and M. Aono, Surf. Sci. 377-379, 676 (1997).

${ }^{3}$ P. L. McEuen, N. G. Chopra, A. Zettl, A. Thess, and R. E. Smalley, Science 275, 1922 (1997); R. P. Rodrigues, Jin-Ha Hwang, and W. P. Dravid, J. Electroceram. 3:3, 245 (1999).

${ }^{4}$ P. Bøggild, T. M. Hansen, C. L. Petersen, F. Grey, T. Hassenkam, T. Bjørnholm, I. Shiraki, and S. Hasegawa, Proceedings of the 9th International Conference on Production Engineering in Osaka (9th ICPE), 1999, p. 832 .

${ }^{5}$ T. Fujii et al., J. Vac. Sci. Technol. B 9, 666 (1991).

${ }^{6}$ T. Junno, S. B. Carlsson, H. Xu, L. Montelius, and L. Samuelson, Appl. Phys. Lett. 72, 548 (1998).

${ }^{7}$ M. Wendel, H. Lorenz, and J. P. Kotthaus, Appl. Phys. Lett. 67, 3732 (1995).

${ }^{8}$ M. Wendel, B. Irmer, J. Cortes, R. Kaiser, H. Lorenz, J. P. Kotthaus, A. Lorke, and E. Williams, Superlattices Microstruct. 20, 349 (1996).

${ }^{9}$ H. W. P. Koops, G. Schössler, A. Kaya, and M. Weber, J. Vac. Sci. Technol. B 14, 4105 (1996).

${ }^{10}$ H. W. P. Koops, J. Kretz, M. Rudolph, and M. Weber, J. Vac. Sci. Technol. B 11, 2386 (1993).

${ }^{11}$ Q. Niu, C. Chang, and C. K. Smith, Phys. Rev. Lett. 51, 5502 (1995).

${ }^{12}$ T. Gramespacher and M. Büttiker, Phys. Rev. Lett. 81, 2763 (1998). 